\title{
The Role of Supportive Therapy in the Era of Modern Adjuvant Treatment - Current and Future Tools
}

\author{
Rupert Bartsch Guenther G. Steger \\ Department of Medicine I and Cancer Centre, Clinical Division of Oncology, Medical University of Vienna, Austria
}

\section{Key Words}

Adjuvant treatment - Breast cancer - Growth factors . Side effects · Supportive care

\section{Summary}

Recent advances in adjuvant treatment of breast cancer have improved progression-free and overall survival. Optimal management of treatment-induced side effects has therefore gained further importance. This review cannot provide a comprehensive overview of treatment-related toxicity and its management, but focuses on important new developments in the field of supportive therapy. Erythropoietins, while highly effective in treating chemotherapy-induced anaemia, may have detrimental effects on outcome, and should only be used with the aim to reduce the number of whole blood transfusions. Granulocyte colony-stimulating factors were a prerequisite for development of dose-dense regimens, and are also necessary in many anthracycline/taxane combination regimens. A potential tumour-stimulating effect was not proven in solid cancers. For side effects of conventional chemotherapy, such as mucositis, nausea, or diarrhoea, regularly updated guidelines may improve symptom control. Overall, modern supportive treatment tools will further reduce treatment-related mortality and help increase quality of life.

\section{Schlüsselwörter \\ Adjuvante Therapie - Brustkrebs - Wachstumsfaktoren . Nebenwirkungen · Supportive Therapie}

\section{Zusammenfassung}

Die jüngsten Fortschritte in der adjuvanten Therapie von Brustkrebs haben zu einer Verbesserung des rezidivfreien Überlebens sowie des Gesamtüberlebens geführt. Dadurch hat eine optimale Behandlung der therapieassoziierten Nebenwirkungen eher an Bedeutung gewonnen. Dieser Artikel kann keinen umfassenden Überblick über das Management von therapieassoziierten Nebenwirkungen bieten, sondern versucht wichtige neue Entwicklungen im Bereich der Supportivbehandlung aufzuzeigen. Erythropoetine wurden lange Zeit relativ unkritisch zur Behandlung der Anämie bei Tumorpatienten herangezogen. Neue Studienergebnisse, die ein schlechteres Outcome nach Therapie mit Erythropoetinen zeigten, führten jedoch zur Empfehlung, dass diese Substanzen nur mit dem Ziel, die Anzahl an Bluttransfusionen zu reduzieren, angewendet werden sollten. Granulozyten-stimulierende Wachstumsfaktoren (G-CSF) haben dosisdichte Chemotherapieregime ermöglicht und sind für viele Anthrazyklin/Taxan-Kombinationstherapien notwendig. Ein möglicher tumorstimulierender Effekt konnte für solide Tumoren nicht nachgewiesen werden. Von Fachgesellschaften existieren Empfehlungen zur Behandlung von Nebenwirkungen der konventionellen Chemotherapie, wie Mukositis, Übelkeit und Durchfall. Breite Anwendung dieser Guidelines dürfte zu einer Verbesserung der Behandlungsstandards führen. Insgesamt können moderne supportive Behandlungsmethoden zu einer deutlichen Verbesserung der Lebensqualität sowie zu einer Reduktion der therapieassoziierten Mortalität beitragen.

\begin{tabular}{ll}
\hline KARGER & ๑ 2009 S. Karger GmbH, Freiburg \\
Fax +497614520714 & Accessible online at: \\
Information@Karger.de & www.karger.com/brc \\
www.karger.com &
\end{tabular}




\section{Introduction}

Modern therapy has effectively decreased cancer-related mortality in breast cancer in many fields of haematology and oncology. For example, dose-dense regimens were found to be more effective than conventionally dosed therapy; those regimens, as are most of the taxane-based combinations, are associated with increased risk for prolonged neutropenia and neutropenic fever, thereby making prophylactic use of granulocyte colony-stimulating factors (G-CSF) necessary. In general, in adjuvant therapy of breast cancer, maintenance of dose density (absolute dose and dose interval) is paramount for the efficacy of chemotherapy. Therefore, G-CSF support has a direct influence on treatment outcome.

Anaemia remains a major concern in cancer patients, and the use of erythropoietin-stimulating agents increased over the years. Preclinical data even suggested better activity of anti-tumour treatment in tissue with high oxygen levels. This assumption resulted in the design of clinical trials aiming at high haemoglobin concentrations. In those studies, however, a negative effect on survival was observed. Later trials reported similar results. Therefore, in 2007, the American Food and Drug Administration (FDA) issued a warning to use erythropoietins only in cancer patients receiving chemotherapy in order to reduce the number of necessary whole blood transfusions.

Treatment of side effects from conventional chemotherapy may still be challenging in some patients. While a new class of substances has become available for the prophylaxis of chemotherapy-induced nausea and vomiting (NK-1 receptor antagonists), no new drugs are currently available for the therapy of diarrhoea. In the treatment of chemotherapy-induced mucositis, specific growth factors have been proven effective in clinical trials.

For this review, data were obtained from current guidelines as issued by the American Society of Clinical Oncology (ASCO), the European Society of Medical Oncology (ESMO), and the European Organisation for Research and Treatment of Cancers (EORTC), by searching Medline database and abstracts from the ASCO annual meeting, ECCO, ESMO, and the San Antonio Breast Cancer Symposium, using combinatorial search terms that included 'adjuvant therapy', 'anaemia', 'breast cancer', 'chemotherapy', 'erythropoietin', 'G-CSF', 'filgrastim', 'pegfilgrastim', 'neutropenia', 'neutropenic fever', 'nausea', 'emesis', 'diarrhoea', 'mucositis', 'supportive care', 'dose dense therapy' and 'growth factor support'.

\section{Erythropoietins in Breast Cancer}

\section{Background}

In cancer patients, anaemia is a widespread and often debilitating problem with a major impact on quality of life. Incidence varies depending on tumour type, stage, and anti-cancer treatment $[1,2]$. Severe anaemia, however, is a rare event in the relatively young and healthy population receiving adju- vant therapy for breast cancer. Multiple factors contribute to the development of tumour-associated anaemia: haemolysis, gastrointestinal bleeding, deficiency in vitamin B12 or folinic acid, and myelosupression by chemotherapy or irradiation; erythrocyte production may also be directly impaired by bone marrow infiltration. Cisplatin may add to anaemia by reduction of erythropoietin levels due to renal damage [3-6]. Furthermore, malignant disease leads to the release of cytokines, especially interferon- $\gamma$, interleukin- 1 , and tumour necrosis factor (TNF)- $\alpha$. Those cytokines inhibit renal erythropoietin production and interact with normal ferrokinetics [7].

\section{Symptoms and Consequences of Anaemia}

Clinical symptoms of anaemia are highly variable and dependent on absolute haemoglobin levels, haemoglobin kinetics, and comorbidities [7]. Moderate anaemia may cause exerciserelated shortness of breath, palpitation, and headache, while severe cases will ultimately result in organ damage. The main symptom of anaemia in cancer patients, however, is fatigue, a term summarizing the impact of anaemia on quality of life and the ability to perform activities of daily life $[8,9]$. Consequently, fatigue correlates with higher levels of anxiety and depression [10]. Furthermore, in malignant lymphoma as well as in a number of solid cancers, anaemia is known to correlate with impaired survival [11]. It is, however, important to note that fatigue may develop independently from anaemia as a direct consequence of adjuvant treatment.

Based on the assumption that higher oxygen levels in tumour tissue will confer better response to irradiation and chemotherapy, a number of erythropoietin trials were initiated that ultimately showed a worse outcome in the intervention group [12]. A recent meta-analysis strengthened those data: Results of nearly 14,000 patients included in 53 trials were analysed. Independently of anti-cancer treatment, the use of erythropoietins resulted in increased mortality during the study period (hazard ratio (HR) 1.17 ; $95 \%$ confidence interval (CI) 1.06-1.30) and impaired overall survival [13].

\section{Erythropoietins - Substances}

Low levels of endogenous erythropoietin and consequently a role for erythropoiesis-stimulating agents (ESAs) in cancer patients were first suggested in 1990 by Miller et al. [14]. While no comparative analysis between the different commercially available agents has been published to date, it is suggested that the different pharmacodynamic properties do not result in different biologic activity [15]. Therefore, for this review, no differences was made between the substances, and the term erythropoietins or ESAs is used for all substances.

Erythropoietins have proven activity in reducing levels of fatigue and number of whole blood transfusions. Whole blood transfusions are believed to have an immunosuppressive effect, therefore resulting in detrimental effects on cancer treatment $[16,17]$. Those immune effects associated with transfusion have been referred to as the TRIM effect (transfusion- 
Table 1. Studies of erythropoiesis-stimulating agents (ESAs) in cancer patients with negative outcome

\begin{tabular}{|c|c|c|c|c|}
\hline Author [Ref.] & $\begin{array}{l}\text { Patients, } \\
\mathrm{n}\end{array}$ & Tumour entity & $\begin{array}{l}\text { Haemoglobin, } \\
\mathrm{mg} / \mathrm{dl}\end{array}$ & Outcome \\
\hline Leyland-Jones [19] & 939 & $\begin{array}{l}\text { breast cancer, } \\
\text { stage IV }\end{array}$ & $\geq 13$ & $\begin{array}{l}\text { lower survival at } 12 \\
\text { months }(\mathrm{p}=0.01)\end{array}$ \\
\hline Henke [20] local & 351 & head and neck & $\begin{array}{l}\geq 12 \text { in women } \\
\geq 13 \text { in men }\end{array}$ & $\begin{array}{l}\text { increased risk for local } \\
\text { failure }(\mathrm{p}=0.007) \text { and } \\
\text { death }(\mathrm{p}=0.02)\end{array}$ \\
\hline Wright [21] & 70 & NSCLC, stage IV & $12-14$ & $\begin{array}{l}\text { shorter survival } \\
(\mathrm{p}=0.04)\end{array}$ \\
\hline Goldberg [22] & 552 & head and neck & $14-15.5$ & $\begin{array}{l}\text { increased risk for local } \\
\text { failure }(p=0.01)\end{array}$ \\
\hline $\begin{array}{l}\text { Anaemia of Cancer } \\
\text { Study [21] }\end{array}$ & 989 & $\begin{array}{l}\text { cancer patients not } \\
\text { receiving chemotherapy } \\
\text { or irradiation }\end{array}$ & $\begin{array}{l}\geq 13 \\
y\end{array}$ & $\begin{array}{l}\text { shorter survival } \\
(p=0.008)\end{array}$ \\
\hline $\begin{array}{l}\text { Lymphoid Cancers } \\
\text { Anaemia Study [21] }\end{array}$ & 344 & $\begin{array}{l}\text { lymphoproliferative } \\
\text { disorders }\end{array}$ & $\begin{array}{l}<15 \text { in women } \\
<14 \text { in men }\end{array}$ & shorter survival \\
\hline
\end{tabular}

NSCLC $=$ Non-small cell lung cancer. related immune modulation); it summarizes increased cancer recurrence, increased mortality, and increased postoperative bacterial infections [18]. Those observations brought a gradual increase in the use of ESAs, and randomized trials evaluating the beneficial role of erythropoietins in different tumour entities were started. Surprisingly, however, 2 trials conducted by Leyland-Jones et al. [19] and Henke et al. [20] showed a negative effect on oncologic endpoints. These results soon were strengthened by further data and ultimately led to an FDA warning on the use of erythropoietins in cancer patients [12].

\section{Increased Risk of Adverse Events}

The BEST (Breast Cancer Erythropoietin Survival Trial) trial conducted by Leyland-Jones et al. [19] included 939 patients with metastatic breast cancer receiving first-line chemotherapy. Subjects were randomized to receive epoetin alfa 40,000 IU or placebo once a week for a total of 12 months. The study was terminated early due to a significantly higher mortality rate. Other trials also reported an increased risk for adverse events. A study by Wright et al. [21] evaluating epoetin alfa in stage IV non-small cell lung cancer was stopped after recruiting 70 of 300 preplanned patients because a significantly higher risk for death was observed in the intervention group (HR 1.84; $\mathrm{p}=0.04$ ). Goldberg et al. [22] used darbepoetin alfa in patients with advanced head and neck cancer. In the 522 patients randomized, the authors reported a $10 \%$ increase in the risk for locoregional failure $(\mathrm{p}=0.01)$ as well as a trend towards shorter overall survival. Another trial conducted in patients with lymphoproliferative disorders also brought negative results [23]. In this study, the target haemoglobin level was defined as $<15 \mathrm{mg} / \mathrm{dl}$ in women and $<14 \mathrm{mg} / \mathrm{dl}$ in men. Importantly, a further study aimed to define the role of ESAs in non-myeloid cancer patients without chemotherapy or irradiation. Similar to the other trials, this Anemia of Cancer Study, which accrued nearly a thousand patients, found a shorter overall survival in the darbepoetin alfa group [23]. Studies are summarized in table 1.

To a certain degree, those results may be explained by an increased risk of thromboembolic events. Still, another concern with ESAs in oncology is a potential direct effect on tumour growth, as tumour cells as wells as endothelial cells may express erythropoietin receptors. Also, erythropoietin-receptors have diverse biological functions in non-haematopoietic tissue. Amongst others, they have a role in wound healing and, importantly, angiogenesis [24, 25]. To date, however, it has not been resolved whether the receptors identified on tumour cells are in fact erythropoietin receptors, as the assays used are known to lack specificity. Furthermore, it is has not been clarified if those receptors are functional and result in active erythropoietin receptor signalling [26]. That of course remains an important area of future research.

\section{Current Recommendations}

Based on the data presented above, the FDA clearly discourages an uncritical use of ESAs in oncology. As those substances are licensed for patients receiving chemotherapy in order to reduce the need for whole blood transfusions, the following recommendation was given in 2007: ESAs may increase the risk of death and serious cardiovascular events when administered to target haemoglobin levels $>12 \mathrm{~g} / \mathrm{dl}$. Therefore, physicians should 'use the lowest dose that will gradually increase the haemoglobin concentration to the lowest level sufficient to avoid the need for blood transfusions' [12].

\section{Granulocyte Colony-Stimulating Factors}

\section{Background}

Dose-dense and dose-escalated chemotherapies are associated with increased risk of prolonged neutropenia and neutropenic 
fever. Indeed, only the availability of growth factors made the development of dose-dense regimens possible. Chemotherapy regimens are usually classified according to their risk of febrile neutropenia (FN). When a certain threshold is exceeded, primary prophylaxis of FN with G-CSF is recommended. As defined by current ASCO guidelines, this threshold is an incidence of FN of approximately 20\% [27]. In regimens with lower risk, further considerations are necessary. Clinical factors associated with a higher incidence of FN are low performance status, prior episode of FN, extensive prior therapy, combination of chemotherapy with irradiation, advanced cancer, serious comorbidities, and bone marrow infiltration. A number of studies clearly points out that patients older than 65 years are at increased risk of developing FN [28-30]. In any of those circumstances, current guidelines recommend the use of primary prophylaxis even in regimens with less than $20 \%$ risk of FN, especially if treatment is administered with curative intent [27]. Table 2 provides an overview of breast cancer regimens commonly used in the neoadjuvant and adjuvant setting and their specific risk of FN.

\section{Studies of G-CSF in Breast Cancer}

As outlined above, dose-dense regimens require G-CSF support. In breast cancer, maintenance of absolute dose and dose intervals is important for treatment efficacy. This was already observed with classical adjuvant CMF (cyclophosphamide, methotrexate, 5-fluorouracil (5-FU)), where a dose intensity of $<85 \%$ of the original Bonnadonna regimen resulted in increased risk for relapse and death [31].

In a highly influential study published in 2003, Citron et al. [32] compared dose-dense to conventionally scheduled adjuvant treatment. In this trial, a significant benefit was found for the dose-dense group. Based upon those results and confirmatory data [33, 34], dose-dense regimens are today deemed standard in North America. Likely independent of G-CSF support, a just recently observed potential drawback of dosedense treatment is a decline in pulmonary function, as defined by a significant reduction of carbon monoxide diffusion capacity [35]. This observation may be important for women with pre-existing lung disease, and should be further investigated.

Anthracycline plus taxane combinations yield the highest response rates achievable with conventional chemotherapy in the treatment of breast cancer [36]. This combination regimen has a rate of $\mathrm{FN}$ well above $20 \%$ and therefore makes the use of prophylactic G-CSF support necessary.

In a neoadjuvant trial of docetaxel plus epirubicin given every 3 weeks with G-CSF-support conducted by the Austrian Breast and Colorectal Study Group (ABCSG-14), only $7.6 \%$ of patients developed neutropenic fever [37]. Wenzel et al. [38] reported no case of grade IV toxicity or FN with the combination of epirubicin, docetaxel, and capecitabine plus pegfilgrastim as neoadjuvant treatment. Results from an exploratory analysis of the GeparTRIO study suggested a higher efficacy of pegfilgrastim as compared to filgrastim as prophy-
Table 2. Risk of grade III and IV neutropenia with commonly used neoadjuvant and adjuvant regimens

\begin{tabular}{lll}
\hline Regimen & $\begin{array}{l}\text { Incidence of } \\
\text { FN, } \%\end{array}$ & \\
\hline Adjuvant & & \\
FEC100 & 8.4 & {$[96]$} \\
AC $\rightarrow$ paclitaxel (all dose levels) & 3 & {$[25]$} \\
FEC100 $\rightarrow$ docetaxel & 11.2 & {$[96]$} \\
TAC & 17 & {$[97]$} \\
TAC + G-CSF & 1 & {$[97]$} \\
TC $\times 4$ & 5 & {$[98]$} \\
A $\rightarrow$ C $\rightarrow$ paclitaxel dose-dense + G-CSF & 2 & {$[29]$} \\
AC $\rightarrow$ paclitaxel dose-dense + G-CSF & 2 & {$[25]$} \\
Neoadjuvant & & \\
Epirubicin/docetaxel + G-CSF & 7.6 & {$[34]$} \\
TEX + G-CSF & 0 & {$[35]$} \\
\hline
\end{tabular}

$\mathrm{FN}=$ Febrile neutropenia; G-CSF = granulocyte colony-stimulating factor; FEC100 = 5-FU, epirubcin $100 \mathrm{mg} / \mathrm{m}^{2}$, cyclophosphamide; $\mathrm{AC}=$ doxorubicin, cyclophosphamide; $\mathrm{TAC}=$ docetaxel, doxorubicin, cyclophosphamide; TEX = docetaxel, epirubicin, capecitabine.

laxis of FN. Patients received 6-8 cycles of TAC (docetaxel, doxorubicin, cyclophosphamide), a regimen associated with a FN risk $>20 \%$, with either ciprofloxacine, filgrastim, pegfilgrastim, or different combinations. The pegfilgrastim group had a significantly lower incidence of FN (7\%, or 5\% when pegfilgrastim was combined with ciprofloxacine, as compared to $18 \%$ with filgrastim and $22 \%$ with ciprofloxacin alone; $\mathrm{p}<$ 0.001) [39]. Therefore, pegfilgrastim seems to be the optimal FN prophylaxis in adjuvant treatment. Of course, aspects of costs need to be taken into consideration. As non-pegylated G-CSF biosimilars are becoming available, the relative cost effectiveness of pegfilgrastim may be reduced.

\section{Potential Drawbacks}

Although clear evidence is lacking, concerns were raised on a potential tumour-stimulatory effect of G-CSF support. Indeed, in acute myeloid leukaemia (AML), G-CSF may increase tumour cell count. These observations even led to the concept of G-CSF priming before chemotherapy. Different studies, however, were not able to prove that this approach was beneficial over more conventional therapy [27].

In breast cancer, Smith et al. [40] reviewed data from all adjuvant NSABP breast cancer trials that tested regimens containing both doxorubicin and cyclophosphamide to characterize the incidence of subsequent AML and myelodysplastic syndrome (MDS). This group analyzed 6 adjuvant trials in which different doses of doxorubicin/cyclophosphamide (AC) were used. The more intense regimens had mandatory growth factor support. While the overall incidence of secondary haematological malignancies in $>8,000$ patients (representing 61,810 patient years of follow-up) included was relatively low $(0.5 \%)$, it was markedly increased in patients on more in- 
Fig. 1. Recommendations for the use of antiemetics.

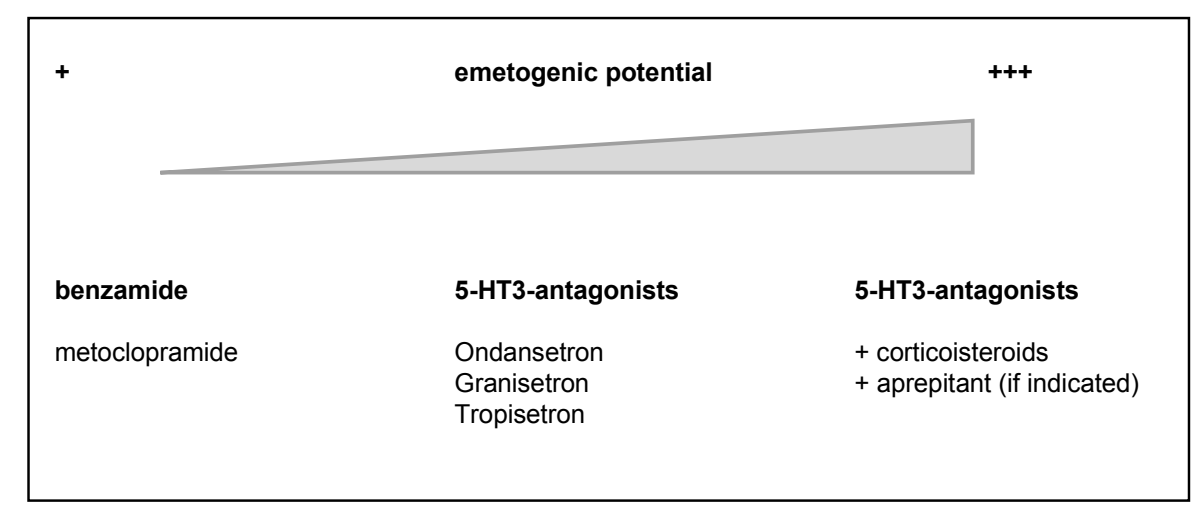

Table 3. Emetogenic potential of commonly used cytotoxics (without prophylaxis)

\begin{tabular}{ll}
\hline Substance & Emetogenic potential, \% \\
\hline Cisplatin $>50 \mathrm{mg} / \mathrm{m}^{2}$ & $>90\left(12-48 \mathrm{~h}^{\mathrm{a}}\right)$ \\
Cyclophosphamide $>1,500 \mathrm{mg} / \mathrm{m}^{2}$ & $>90\left(12-48 \mathrm{~h}^{\mathrm{a}}\right)$ \\
Methotrexate $>1,000 \mathrm{mg} / \mathrm{m}^{2}$ & $60-90$ \\
Cyclophosphamide $>750-<1,500 \mathrm{mg} / \mathrm{m}^{2}$ & $60-90$ \\
Doxorubicin $>60 \mathrm{mg} / \mathrm{m}^{2}$ & $60-90$ \\
Cyclophosphamide $<750 \mathrm{mg} / \mathrm{m}^{2}$ & $30-60$ \\
Epirubicin $<90 \mathrm{mg} / \mathrm{m}^{2}$ & $30-60$ \\
Docetaxel, paclitaxel & $10-30$ \\
5-Fluorouracil $<1,000 \mathrm{mg} / \mathrm{m}^{2}$ & $10-30$ \\
\hline
\end{tabular}

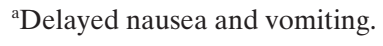

tense AC requiring G-CSF support (1.1\%). While a direct effect of G-CSF upon this increase cannot be ruled out, it must be kept in mind that this observation does not stem from a randomized trial and therefore must be deemed exploratory. Yet another study, analyzing data from the SEER database brought similar results: In a total of 5,500 women, the HR for AML or MDS among those treated with G-CSF or granulocyte-macrophage colony-stimulating factor (GM-CSF) compared with those who were not was 2.14 (95\% CI 1.12-4.08) [41]. Authors therefore concluded that the use of G-CSF was associated with a doubling in the risk of subsequent AML or MDS among the population studied, although the absolute risk remained low. While currently there are no results from randomized prospective trials available, G-CSF use should not be assumed to be risk-free. Apart from a putatively increased risk of secondary MDS, the best known side effect of G-CSFsupport in solid tumour patients is pain which is usually easily manageable with paracetamol.

\section{Neutropenic Infections}

Neutropenia is one of the most important risk factors for infection. Additional factors contributing markedly to increased risk of infection include damage of skin or mucous membranes [42]. The common sites of infection in cancer patients include the skin and mucous membranes, the digestive system, the respiratory system, the urinary system, the central nervous system, and the skin and tissue around a vascular access device [43]. While in many patients with neutropenic fever exact localisation of the infection may not be possible, immediate empiric antibiotic therapy must be started in order to prevent life-threatening complications [42]. The recently updated National Comprehensive Cancer Network (NCCN) guidelines provide a comprehensive overview of the optimal management of neutropenic infections in cancer patients [44].

\section{Side Effects of Conventional Chemotherapy}

\section{Background}

Optimal management of side effects of conventional chemotherapy remains a challenge. As a large number of reviews and guidelines have already been published in the fields of nausea, diarrhoea, and mucositis [45-47], this review concentrates on recent developments.

\section{Nause and Vomiting}

The 3 most widely applied classes of antiemetic substances in cancer therapy are 5-HT3 serotonin receptor antagonists, corticosteroids (betamethasone, dexamethasone), and the single currently commercially available NK-1 receptor antagonist, aprepitant [45]. For an overview of the emetogenic potential of cytotoxic agents commonly used in breast cancer patients and its prophylaxis see table 3 and figure 1.

The NK-1 antagonist aprepitant binds to and blocks the NK-1 receptor, thereby inhibiting the binding of its natural ligand, substance P [48]. This cytokine, when administered to animals, causes emesis. Of note is the activity also in cisplatinassociated delayed nausea [45]. Following phase II trials [49, 50], 3 randomized phase III trials were initiated. Here, the role of aprepitant was tested in patients on chemotherapeutic regimens of high (cisplatin) and moderate emetogenic potential (anthracyclines, cyclophosphamide).

In 2 cisplatin trials, a total of 1,043 patients were randomized to receive the standard combination of ondansetron plus dexamethasone with or without aprepitant. The pooled analysis of those studies reported an improvement by $20 \%$ 
in the prevention of vomiting for the 5-day period after cisplatin administration $(p<0.001)$ [51]. Noteworthy, efficacy was apparently highest in the prevention of delayed emesis, defined as symptoms starting $>24 \mathrm{~h}$ after the administration of chemotherapy (21\% improvement as compared to $13 \%$ improvement in acute emesis). This reflects the fact that 5HT3 antagonists have insufficient activity in the prevention of delayed emesis. In a third randomized study, aprepitant was administered in 857 women receiving anthracycline plus cyclophosphamide chemotherapy for early breast cancer. Again, standard prophylaxis consisted of ondansetron and dexamethasone. With the 3 -drug regimen, complete response (defined according to the ASCO 2006 guidelines as no event of emesis and no administration of rescue medication in the 5day period following chemotherapy administration [45]) was increased by $9 \%(p=0.015)$. Importantly, no increased rate of side effects was reported in the aprepitant group [52]. Those studies established aprepitant as valuable option in patients on chemotherapy of both, highly and moderately emetogenic potential (table 4). In general, a more intensive prophylaxis may be advisable in patients with travel sickness or emesis during pregnancy, as this may be associated with increased risk of chemotherapy-induced emesis.

Questions, however, were raised on the fact that aprepitant is a moderate inhibitor of CYP3A4. This might in theory affect the metabolism of other substrates of CYP3A4, such as corticosteroids, cyclophosphamide, and docetaxel. In the aforementioned study of aprepitant in breast cancer, no increased rate of FN was reported, thus suggesting a comparable exposure to cyclophosphamide in both study groups $[45,52]$. In another study, aprepitant was not found to influence docetaxel pharmacokinetics or toxicity [53]. Therefore, based on current recommendations, no reduction of chemotherapy dose is necessary when aprepitant is administered as antiemetic at the established schedule. However, dose reduction of corticosteroids may be considered in cases were they are solely administered in order to prevent chemotherapy-induced nausea and vomiting when combined with aprepitant [45].

Little new data is available on other classes of antiemetics. Butyrophenones, phenothiazines and cannabinoids may be considered as adjunct to 5-HT3 antagonists, corticosteroids, and aprepitant when no sufficient effect can be reached. However, they should not be utilized as first-line substances [45]. A general recommendation for the use of antiemetics is provided in figure 1.

\section{Mucositis}

Mucositis is an underestimated side effect of anti-cancer treatment. Traditionally, awareness of mucositis was higher in haematology, as the incidence was higher with high-dose regimens as often administered in haematological malignancies. Still, mucositis is a major problem also in the management of solid tumours, as treatment delays and dose reductions may result which in turn may compromise survival [54].
Table 4. Randomized studies of aprepitant in chemotherapy of highly and moderately emetogenic potential

\begin{tabular}{lcll}
\hline Chemotherapy & Patients, $\mathrm{n}$ & $\begin{array}{l}\text { Complete response }^{\mathrm{a}} \\
\text { improvement over } \\
\text { control, \% }\end{array}$ & Reference \\
\hline Cisplatin & $1,043^{\mathrm{b}}$ & $20(\mathrm{p}<0.001)$ & {$[43]$} \\
Anthracycline & 857 & $9(\mathrm{p}=0.015)$ & {$[44]$} \\
\hline
\end{tabular}

${ }^{\mathrm{a}}$ Complete response defined as no event of emesis and no administration of rescue medication in the 5-day period following chemotherapy administration [37].

${ }^{b}$ Pooled analysis of 2 identical trials of aprepitant in cisplatin-treated patients.

Chemotherapy (and irradiation) causes DNA damage and release of free radicals in the mucosal tissue. Consecutively, with upregulation of genes associated with inflammatory reactions, expression of various pro-inflammatory cytokines is increased (e.g. interleukin-6, tumour necrosis factor- $\alpha$ ). This confers apoptosis of mucosal cells, which in turn will lead to development of ulcerations and local infection [55]. The risk of severe (grade 3 or 4) mucositis in breast cancer patients is relatively low. In a recently published review on the incidence and treatment of mucositis in solid tumour patients, the observed incidence ranged from $2.29 \%$ with sequential chemotherapies to $8.33 \%$ in anthracycline plus taxane combinations [46, 47]. While those incidence rates may be lower when compared to lymphoma treatment, it appears higher than in colorectal or lung cancers [56]. Apart from the type of chemotherapy, genetic susceptibility also plays a role [57].

The most important factors, both for treatment and prevention, are basic oral care, simple mouth washes, and systemic analgesics [54]. This was already recommended in the original clinical practice guidelines as published in 2004 [58]. However, little data is available on standard-dose chemotherapy as used in breast cancer. Furthermore, there is no widely agreed upon regimen, and not all protocols did include antimycotics $[58,59]$. An even wider range of topical preparations has been studied in the treatment of chemotherapy-induced mucositis. In standard-dose chemotherapy, chlorhexidine-containing mouthwash was unable to exert any beneficial effect on the severity or duration of symptoms [60]. This substance therefore is not recommended for the treatment of mucositis in current guidelines [58]. The use of lidocain, although widely applied, has also not proved beneficial; concerns regarding systemic absorption through damaged mucosal tissue have led to discouragement of local anaesthetics in the treatment of mucositis [58].

While no data is available on the potential role in standarddose chemotherapy, keratinocyte growth factor-1 (KGF1, palifermin) has proven effective in the prevention of mucositis in patients receiving high-dose chemotherapy [61]. This renders palifermin attractive for trials on mucositis therapy. The use of GM-CSF-containing mouthwashes did, however, not prove 
effective in the treatment of chemotherapy-induced mucositis [62]. Hence, recent years have brought no major advance in the prevention or treatment of mucositis in breast cancer patients.

\section{Diarrhoea}

Diarrhoea is a serious and potentially life-threatening side effect associated with many chemotherapeutic agents. Although a high incidence of chemotherapy-induced diarrhoea is reported, the condition is often recognized late and poorly managed [63]. Fluid and electrolyte loss may result in dehydration and ultimately renal insufficiency, also the rate of infectious complications is increased [46]. Furthermore, as with other serious side effects, chemotherapy-induced diarrhoea may lead to dose reductions and treatment delays, thereby impairing activity of anti-cancer treatment [64]. The combination of irinotecan and 5-FU may pose a special threat for developing diarrhoea, and is associated with an increased risk of treatment-related mortality $[65,66]$. In breast cancer, diarrhoea is commonly observed with capecitabine, but may also occur in regimens including docetaxel or vinorelbine $[67,68]$.

Treatment recommendations are provided in the current ASCO guidelines. In short, depending on the severity of the symptoms, treatment may include loperamide, fluoroquinolones, intravenous fluids, and in serious cases octreotide [46]. Relatively new data is available on octreotide, a long-acting somatostatin analogue: It is considered an option if other treatments fail to provide symptom control [46]. Optimal dose and schedule have not yet been defined, however, a dose escalation study showed that doses of up to $2,500 \mu \mathrm{g}$ three times a day (tid) are safe, and resolution of symptoms increased with the octreotide dose [69]. The only prospective comparison of different octreotide dose levels compared 100-500 $\mu \mathrm{g}$ tid in patients with grade III diarrhoea, who had failed on loperamide. In this study, $500 \mu \mathrm{g}$ octreotide tid was significantly more effective, with $90 \%$ of patients achieving complete resolution of symptoms as compared to $61 \%$ in the low-dose group $(p<0.05)$ [70]. ASCO guidelines therefore suggest an upward titration of octreotide dose until symptoms are controlled [46].

\section{Further Side Effects}

Osteoporosis and its prevention with bisphosphonates were heavily researched upon in postmenopausal women on adjuvant aromatase inhibitors. In premenopausal women with early breast cancer undergoing adjuvant chemotherapy, risedronate did not prevent bone loss as compared to placebo [71]. Interestingly, a trial utilizing zoledronic acid brought different results: Premenopausal women receiving chemotherapy sustained significant bone loss, whereas bone mineral density remained stable in women who received zoledronic acid. Authors of this study concluded that the administration of zoledronic acid during the first year of chemotherapy is an effective and well tolerated strategy for preventing bone loss
[72]. In the light of these contradictory results, and bearing in mind clinical data suggesting a direct anti-tumour effect of zoledronic acid in premenopausal patients receiving endocrine therapy [73], the exact role of bisphosphonates in the adjuvant setting awaits further clarification.

Polyneuropathy is another side effect with a potentially major impact on quality of life. Commonly, this side effect is associated with the use of microtubule-stabilizing agents (MTSA). Severe neuropathy (grade 3 and 4) may be observed in up to $30 \%$ of patients treated with taxanes or epothilones [74]. The incidence of MTSA-induced neuropathy seems to depend on the MTSA dose per treatment cycle, the schedule of treatment, and the duration of the infusion. The exact mechanism by which neuropathy develops remains poorly understood [75]. Available data suggest that vitamin E may attenuate the development of chemotherapy-induced neuropathy, but more data regarding its efficacy and safety should be obtained prior to its general use in patients. Other agents that look promising in preliminary studies but need further evaluation include glutamine, glutathione, $\mathrm{N}$-acetylcysteine, oxcarbazepine, and xaliproden. Effective treatment of established polyneuropathy, however, has yet to be found [76].

\section{Management of Trastuzumab-Related Toxicity}

\section{Background}

Trastuzumab (rhMab4D5), a monoclonal humanized antibody targeting Her-2, is currently the only molecular targeted therapy registered for use in early breast cancer. Different mechanisms of action have been suggested: Inhibition of downstream signalling pathways, inhibition of extracellular Her-2 proteolysis, internalization and degradation of the Her2 receptor protein, cell cycle arrest, inhibition of DNA repair, as well as antibody-dependent cellular cytotoxicity [77, 78]. In addition, trastuzumab may sensitize tumour cells to the cytotoxic effects of conventional chemotherapy [79].

\section{Cardiac Toxicity}

In healthy tissue, Her-2 signalling has a role in the regulation of normal cell processes, like differentiation, survival, and repair mechanism [80]. Cardiac myocytes, for instance, are dependent on Her-2 activation in their response to cellular stress [81]. In the adjuvant setting, approximately $5 \%$ of patients are expected to develop some form of cardiac function impairment, and $1 \%$ may develop symptomatic congestive heart failure (CHF) [82-84]. In most cases, the systolic dysfunction appears to be reversible [85], still, close monitoring of patients on trastuzumab treatment is mandatory. An increased risk for developing a drop in left ventricular ejection fraction (LVEF) was observed in patients of old age and with known hypertension; other risk factors include pre-existing diabetes, coronary artery disease, and valvular dysfunction [84, 85]. It is important to remember that trastuzumab as single agent confers a 
very low risk of severe cardiac toxicity, while the risk is highest with the combination of trastuzumab and anthracyclines. These agents are well known to be associated with cumulative cardiotoxicity. Putative mechanisms of action are apoptosis of cardiac myocytes through free radicals and activation of a pro-apoptotic MAP kinase pathway, pathologic changes of myofilaments, as well as reduced muscular protein syntheses [86-90].

\section{Cardiac Surveillance}

Keefe proposed a surveillance algorithm for controlling cardiac function of breast cancer patients on trastuzumab [91]. Cardiac function should be controlled with echocardiography or MUGA scan every 6 months. If a drop $>10 \%$ from initial measurement or to LVEF levels $<50 \%$ is observed, close surveillance with repeated LVEF measurements every 4 weeks is suggested. In asymptomatic patients, antibody treatment should be stopped when a drop of $>20 \%$ points to $<40 \%$ is observed, or when LVEF falls below 30\%. LVEF measurements should then be repeated every 4 weeks, and antibody therapy may be resumed when LVEF reaches normal levels. In the case of symptomatic $\mathrm{CHF}$, antibody treatment should be stopped and adequate treatment started (table 5). As outlined above, most cases of trastuzumab-associated CHF appear to be reversible [85]. Supportive therapy consists of standard medical treatment with ACE inhibitors, beta blockers, and diuretics if indicated according to current guidelines [92].

\section{Further Side Effects}

Other possible side effects of trastuzumab therapy consist mainly of anaphylactic reactions; however, the HERA trial reported a minimally increased risk of infections (22 patients $(1.3 \%)$ vs. 7 patients $(0.4 \%)$ in the control group) [83], and the combined analysis of the NSABP B-31 and NCCTG N9831 trials reported rare cases of interstitial pneumonitis that in some cases appeared to be related to trastuzumab. In BCIRG 006, there were no significant differences in grade 3 or 4 haematological or non-haematological adverse events among the 3 treatment arms [93]. Also, in the FinHER trial, no differences
Table 5. Algorithm for surveillance of cardiac function in patients on trastuzumab (based on Keefe D [91])

\begin{tabular}{llll}
\hline LVEF & Drop, \% & Screening interval & Trastuzumab \\
\hline$\geq 50 \%$ & no drop & 6 months & go \\
$\geq 30 \%$ but $<50 \%$ & $>10$ & 4 weeks & go \\
$<30 \%$ & $>20$ & 4 weeks & stop $^{\text {a }}$ \\
Symptomatic CHF, & & & stop \\
any LVEF & & &
\end{tabular}

${ }^{a}$ Resume trastuzumab when LVEF returns to normal.

$\mathrm{LVEF}=$ left ventricular ejection fraction; $\mathrm{CHF}=$ congestive heart failure

in the number of adverse events were observed [94]. Interestingly, a recently published paper evaluated gastrointestinal side effects of trastuzumab (i.e. nausea, vomiting, diarrhoea, abdominal pain). Those were observed in as much as $12 \%$ of trastuzumab administrations. As, however, only 46 patients were available for this retrospective chart review, further prospective evaluation of those symptoms appears necessary [95].

\section{Conclusion}

In conclusion, modern supportive treatment has helped improving quality of life of cancer patients receiving chemotherapy. White blood cell growth factors have enabled an increase in chemotherapy dose density, thereby potentially enhancing treatment efficacy. Erythropoietins, while effective in the treatment of chemotherapy-induced anaemia, were found to have a negative impact on survival due to an increased rate of thromboembolic events. Currently, a direct tumour-stimulating effect cannot be ruled out, therefore those substances should be used with due caution.

\section{Conflict of Interest}

The authors did not supply a conflict of interest statement.

\section{References}

1 Coiffer B, Guastella JP, Pujade-Lauraine E, et al. Anemia Study Group. Predicting cancer-associated anemia in patients receiving non-platinum chemotherapy: results of a prospective survey. Eur J Cancer 2001;37:1617-1623

2 Ludwig H, Van Belle S, Barrett-Lee P, et al.: The European Cancer Anaemia Survey (ECAS): a large, multinational, prospective survey defining the prevalence, incidence, and treatment of anaemia in cancer patients. Eur J cancer 2004;40:2293-2306.

-3 Montserrat E, Bosch F, Rozman C: B-cell chronic lymphatic leukemia: recent progress in biology, diagnosis, and therapy. Ann Oncol 1997;8(suppl 1) 93s-101s.
4 Mecadante S, Gebbia V, Marrazzo A, et al.: Anemia in cancer: pathophysiology and treatment. Cancer Treat Rev 2000;26:303-311.

$\checkmark 5$ Groopman JE, Itri LM: Chemotherapy-induced anemia in adults: incidence and treatment. J Natl Cancer Inst 1999;91:1616-1634.

6 Barrett-Lee PJ, Bailey NP, O'Brien ME, et al.: Large-scale UK audit of blood transfusions requirements and anaemia in patients receiving cytotoxic chemotherapy. Brit J Cancer 2000;82:93-97.

7 Grotto HZ: Anaemia of cancer: an overview of mechanisms involved in its pathogenesis. Med Oncol 2008;25:12-21.
8 Stone P, Richardson A, Ream E, et al.: Cancer-related fatigue: inevitable, unimportant and untreatable? Results of a multi-centre patient survey. Cancer Fatigue Forum. Ann Oncol 2000;11:971-975.

9 Curt GA: Impact of fatigue on quality of life in oncology patients. Semin Hematol 2003;37(suppl 6): $14 \mathrm{~s}-17 \mathrm{~s}$.

10 Tchekmediyan NS, Kallich J, McDermott A: The relationship between psychologic distress and cancer related fatigue. Cancer 2003;98:198-203.

11 Tchekmedyian NS: Anemia in cancer patients: significance, epidemiology, and current therapy. Oncology 2002;16:17-24. 
12 Food and Drug Administration: Information for healthcare professionals: erythropoiesis stimulating agents (ESA) (Arenesp (darbepoetin), Epogen (epoetin alfa), and Procrit (epoetin alfa)). www.fda. gov/SiteIndex/ucm126485.htm.

13 Bohlius J, Schmidlin K, Brillant C, et al.: Recombinant human erythropoiesis-stimulating agents and mortality in patients with cancer: a metaanalysis of randomised trials. Lancet 2009;373 $1532-1542$.

14 Miller CB, Jones RJ, Piantadosi S, et al.: Decreased erythropoietin response in patients with anaemia of cancer. N Engl J Med 1990;322:1689-1692.

15 Food and Drug Administration: Oncologic Drugs Advisory Committee Briefing Document. Safety Concerns Associated with Aranesp (darbeopoetin alfa) Amgen, Inc. and Procrit (epoetin alfa) Ortho Biotech, L.P., for the Treatment of Anemia Associated with Cancer Chemotherapy. www.fda.gov/ ohrms/dockets/ac/04/briefing/4037b2_04.pdf.

16 Seidenfeld J, Piper M, Flamm C, et al.: Epoetin treatment of anemia associated with cancer therapy: a systematic review and meta-analysis of controlled clinical trials. J Natl Cancer Inst 2001; 93:1204-1214.

17 Littlewood TJ, Bajetta E, Nortier JW, et al.: Effects of epoetin alfa on hematologic parameters and quality of life in cancer patients receiving nonplatinum chemotherapy: results of a randomized, double-blind, placebo-controlled trial. J Clin Oncol 2001;19:2865-2874.

18 Dellinger EP, Anaya DE: Infectious and immunologic consequences of blood transfusion. Critical Care 2004;8(suppl 2):18S-23S.

19 Leyland-Jones B, Semiglazov V, Pawlicki M, et al. Maintaining normal haemoglobin levels with epoetin alfa in mainly nonanemic patients with metastatic breast cancer receiving first-line chemotherapy: a survival study. J Clin Oncol 2007;25:1027-1032.

20 Henke M, Laszig R, Rübe C, et al.: Erythropoietin to treat head and neck cancer patients with anaemia undergoing radiotherapy: randomised, doubleblind, placebo-controlled trial. Lancet 2003;362: 1255-1260.

21 Wright JR, Ung YC, Julian JA, et al.: Randomized, double-blind, placebo-controlled trial of erythropoietin in non-small-cell lung cancer with diseaserelated anaemia. J Clin Oncol 2007;25:1027-1032.

22 Goldberg P: Danish researchers post long-awaited Aranesp results - ever so discreetly. Cancer Lett 2007;33:1-6.

23 Food and Drug Administration: Oncologic Drugs Advisory Committee Briefing Document. www.fda. gov/ohrms/dockets/ac/07/briefing/2007-4301b2-00index.htm.

24 Seminara P, Minutoli L, Torre V, et al.: Recombinant human erythropoietin stimulates angiogenesis and wound healing in genetically diabetic mouse. Diabetes 2004; 53:2509-2517.

25 George C, Goldstein E, Abashidze A, et al.: Erythropoietin promotes endothelial progenitor cell proliferative and adhesive properties in a PI3-kinase-dependent manner. Cardiovascular Res 2005; 68:299-306.

26 Longmore GD: Do cancer cells express functional erythropoietin receptor? N Engl J Med 2007; 356:2447.

-27 Smith TJ, Khatcheressian J, Lyman GH, et al.: 2006 update of recommendations for the use of white blood cell growth factors: an evidence-based clinical practice guideline. J Clin Oncol 2006;24 3187-3205.
28 Crivellari D, Bonetti M, Castiglione-Gertsch M, et al.: Burdens and benefits of adjuvant cyclophosphamide, methotrexate, and fluorouracil and tamoxifen for elderly patients with breast cancer: The International Breast Cancer Study Group Trial VII. J Clin Oncol 2000;18:1412-1422.

29 Dees EC, O'Reilly S, Goodman SN, et al.: A prospective pharmacologic evaluation of age-related toxicity of adjuvant chemotherapy in women with breast cancer. Cancer Invest 2000;18:521-529.

30 Gelam RS, Taylor SG: Cyclophosphamide, methotrexate, and 5-fluorouracil chemotherapy in women more than 65 years old with advanced breast cancer: The elimination of age trends in toxicity by using doses based on creatinine clearance. $\mathrm{J}$ Clin Oncol 1984;2:1404-1413.

31 Goldhirsch A, Colleoni M, Coates AS, et al.: Adding adjuvant CMF chemotherapy to either radiotherapy or tamoxifen: are all CMFs alike? Ann Oncol 1998;9:489-493.

32 Citron ML, Berry DA, Cirrincione C, et al.: Randomized trial of dose-dense versus conventionally scheduled and sequential versus concurrent combination chemotherapy as postoperative adjuvant treatment of node-positive primary breast cancer: first report of Intergroup Trial C9741/Cancer and Leukemia Group B Trial 9741. J Clin Oncol 2003:21:1431-1439.

33 Dang C, Fornier M, Sugarman S, et al.: The safety of dose-dense doxorubicin and cyclophosphamide followed by paclitaxel with trastuzumab in HER2/neu overexpressed/amplified breast cancer. J Clin Oncol 2008;26:1216-1222.

34 Fornier MN, Seidman AD, Lake D, et al.: Increased dose density is feasible: a pilot study of adjuvant epirubicin and cyclophosphamide followed by paclitaxel, at 10- or 11-day intervals with filgrastim support in women with breast cancer. Clin Cancer Res 2007;13:223-227.

35 Yerushalmi R, Kramer MR, Rizel S, et al.: Decline in pulmonary function in patients with breast cancer receiving dose-dense chemotherapy: a prospective study. Ann Oncol 2009;20:437-440.

36 Nabholtz JM, Riva A: Taxane/anthracycline combinations: setting a new standard in breast cancer? Oncologist 2001;6(suppl 3):5s-12s.

37 Steger GG, Galid A, Gnant M, et al.: Pathologic complete response with six compared with three cycles of neoadjuvant epirubicin plus docetaxel and granulocyte colony-stimulating factor in operable breast cancer: results of ABCSG-14. J Clin Oncol 2007;25:2012-2018.

38 Wenzel C, Bartsch R, Locker GJ, et al.: Preoperative chemotherapy with epidoxorubicin, docetaxel and capecitabine plus pegfilgrastim in patients with primary breast cancer. Anticancer Drugs 2005;16:441-445.

39 Von Minckwitz G, Kümmel S, du Bois A, et al.: Pegfilgrastim + /- ciprofloxacin for primary prophylaxis with TAC (docetaxel/doxorubicin/cyclophosphamide) chemotherapy for breast cancer. Results from the GEPARTRIO study. Ann Oncol 2008;19:292-298.

40 Smith RE, Bryant J, DeCillis A, et al.: Acute myeloid leukemia and myelodysplastic syndrome after doxorubicin-cyclophosphamide adjuvant therapy for operable breast cancer: the National Surgical Adjuvant Breast and Bowel Project Experience. J Clin Oncol 2003;21:1195-1204.

41 Hershman D, Neugut AI, Jacobson JS, et al.: Acute myeloid leukemia or myelodysplastic syndrome following use of granulocyte colony-stimulating factors during breast cancer adjuvant chemotherapy. Natl Cancer Inst 2007;99:196-205.
42 Link H, Boehme A, Cornely OA, et al.: Antimicrobial therapy of unexplained fever in neutropenic patients. Ann Haematol 2003;82(suppl 3): 105S-117S.

43 American Cancer Society: www.cancer.org/docroot/ETO/content/ETO_1_2X_Infections_in_People_with_Cancer.asp.

44 NCCN: www.nccn.org/professionals/physician_gls/ PDF/infections.pdf.

45 Kris MG, Hesketh PJ, Somerfield MR, et al.: American Society of Clinical Oncology Guideline for Antiemetics in Oncology: update 2006. J Clin Oncol 2006;24:2932-2947.

46 Benson AB, AjaniJA, Catalano RB, et al.: Recommended guidelines for the treatment of cancer treatment-induced diarrhea. J Clin Oncol 2004; 22:2918-2926.

47 Keefe DM, Schubert MM, Elting LS, et al.: Updated clinical practice guidelines for the prevention and treatment of mucositis. Cancer 2007;109:820-831.

48 Higa GM, Auber ML, Altaha R, et al.: 5-Hydroxyindoleacetic acid and substance $P$ profiles in patients receiving emetogenic chemotherapy. J Oncol Pharm Pract. 2006;12:201-209.

49 Navari RM, Reinhardt RR, Gralla RJ, et al.: Reduction of cisplatin-induced emesis by a selective neurokinin-1-receptor antagonist. N Engl J Med 1999; 340:190-195.

50 Chwala SP, Grunberg SM, Gralla RJ, et al.: Establishing the dose of the oral NK1 antagonist aprepitant for the prevention of chemotherapy-induced nausea and vomiting. Cancer 2003;97:2290-2230.

51 Warr DG, Grunburg SM, Gralla RJ, et al.: The oral $\mathrm{NK}(1)$ antagonist aprepitant fort he prevention of acute and delayed chemotherapy-induced nausea and vomiting: Pooled data from 2 randomised double-blind, placebo controlled trials. Eur J Cancer 2005;41:1278-1285.

52 Warr DG, Hesketh PJ, Gralla RJ, et al.: Efficacy and tolerability of aprepitant for the prevention of chemotherapy-induced nausea and vomiting in patients with breast cancer after moderately emetogenic chemotherapy. J Clin Oncol 2005;97: 2822-2800.

53 Ngyen P, Hande K, Petty KJ, et al.: Lack of effect of aprepitant on the pharmacokinetics of docetaxel in cancer patients. Cancer Chemother Pharmacol 2005; 55:609-616.

54 Keefe DM: Mucositis management in patients with cancer. Support Cancer Ther 2006;3:154-157.

55 Sonis ST, Elting LS, Keefe D, et al.: Perspectives on cancer therapy-induced mucosal injury: pathogenesis, measurement, epidemiology and consequences for patients. Cancer 2004;23:6-9.

56 Jones JA, Avritscher EBC, Cooksley CD, et al.: Epidemiology of treatment-associated mucosal injury after treatment with newer regimens for lymphoma, breast, lung, or colorectal cancer. Support Care Cancer 2006;14:505-515.

57 Ulrich CM, Yasui Y, Storb R, et al.: Pharmacogenetics of methotrexate: toxicity among marrow transplantation patients varies with methylenetetrahydrofolate reductase C667T polymorphism. Blood 2001; 98:231-234.

58 Rubenstein EB, Peterson DE, Schubert M, et al.: Clinical practice guidelines fort he prevention and treatment of cancer therapy-induced oral and gastrointestinal mucositis. Cancer 2004;100(suppl 9): 2026s-2046s.

59 Cheng KK, Molassiotis A, Chang AM, et al.: Evaluation of an oral care protocol intervention in the prevention of chemotherapy-induced oral mucositis in paediatric cancer patients. Eur J Cancer 2001; 37:2056-2063. 
60 Dodd MJ, Dibble SL, Miaskowski C, et al.: Randomized clinical trial of the effectiveness of 3 commonly used mouth-washes to treat chemotherapyinduced mucositis. Oral Surg Oral Med Oral Pathol Oral Radiol Endod 2000;90:39-47.

61 Spielberger R, Stiff P, Bensinger W, et al.: Palifermin for oral mucositis after intensive therapy for hematologic cancers. N Engl J Med 2004;351: 2590-2598.

62 Valcarcel D, Sanz MA, Sureda A, et al.: Mouth-washings with recombinant human granulozyte-macrophage colony stimulating factor (rhGM-CSF) do not improve grade III-IV oropharyngeal mucositis $(\mathrm{OM})$ in patients with haematological malignancies undergoing stem cell transplantation. Results of a randomized double-blind placebo-controlled study. Bone Marrow Transplant 2002;29:783-787.

63 Richardson G, Dobish R: Chemotherapy induced diarrhea. J Oncol Pharm Pract 2007;13:181-198.

64 Arbuckle RB, Hubr SL, Zacker C, et al.: The consequences of diarrhea occurring during chemotherapy for colorectal cancer: a retrospective study. Oncologist 2000;5:250-259.

65 Rothenberg ML, Meropol NJ, Poplin EA, et al.: Mortality associated with irinotecan plus bolus fluorouracil/leucovorin: summary findings of an independent panel. J Clin Oncol 2001;19:3801-3807

66 Saltz LB, Cox JV, Blande C, et al.: Irinotecan plus fluorouracil and leucovorin for metastatic colorectal cancer. Irinotecan Study Group. N Engl J Med 2000; 343:905-914.

67 Stemmler HJ, Kenngotte S, Diepolder H, et al.: Gastrointestinal toxicity associated with weekly docetaxel treatment. Ann Oncol 2002;13:978-981.

68 Ibrahim NK, Sahin AA, Dubrow RA, et al.: Colitis associated with docetaxel-based chemotherapy in patients with metastatic breast cancer. Lancet 2000;355:281-283.

69 Wadler S, Haynes H, Wiernik PH: Phase I trial of somatostatin analog octreotide acetate in the treatment of fluoropyrimidine.induced diarrhea. J Clin Oncol 1995;13:222-226.

70 Goumas P, Naxakis S, Christopoulou A, et al.: Octreotide acetate in the treatment of fluorouracil induced diarrhea. Oncologist 1998;3:50-53.

71 Hines SL, Mincey BA, Sloan JA, et al.: Phase III randomized, placebo-controlled, double-blind trial of risedronate for the prevention of bone loss in premenopausal women undergoing chemotherapy for primary breast cancer. J Clin Oncol 2009; 27:1047-1053.

72 Hershman DL, McMahon DJ, Crew KD, et al. Zoledronic acid prevents bone loss in premenopausal women undergoing adjuvant chemotherapy for early-stage breast cancer. J Clin Oncol 2008; 26:4739-4745.
73 Gnant M, Mlineritsch B, Schippinger W, et al.: Endocrine therapy plus zoledronic acid in premenopausal breast cancer. N Engl J Med 2009;360: 679-691.

74 Lee JJ, Swain SM.: Peripheral neuropathy induced by microtubule-stabilizing agents. J Clin Oncol 2006;24:1633-1642.

75 Ocean AJ, Vahdat LT: Chemotherapy-induced peripheral neuropathy: pathogenesis and emerging therapies. Support Care Cancer 2004;12:619-25.

76 Wolf S, Barton D, Kottschade L, et al.: Chemotherapy-induced peripheral neuropathy: prevention and treatment strategies. Eur $\mathrm{J}$ Cancer 2008;44:1507-1515.

77 Clynes RA, Towers TL, Presta LG, et al.: Inhibitory Fc receptors modulate in vivo cytotoxicity against tumor targets. Nat Med 2006;6:443.

78 Nahta R, Yu D, Hung MC, et al.: Mechanisms of disease: understanding resistance to Her2-targeted therapy in human breast cancer. Nat Clin Pract Oncol 2006;3:269-280.

79 Pegram M, Hsu S, Lewis G, et al.: Inhibitory effects of combinations of HER-2/neu antibody and chemotherapeutic agents used for treatment of human breast cancers. Oncogene 1999;18:2241-2251.

80 Casalini P, Iorio MV, Galmozzi E, et al.: Role of HER receptors family in development and differentiation. J Cell Physiol 2004;200:343-350.

81 Fukazawa R, Miller TA, Kuramochi Y, et al.: Neuregulin-1 protects ventricular myocytes from anthracycline-induced apoptosis via erbB4-dependent activation of PI3-kinase/Akt. J Mol Cell Cardiol 2003;35:1473-1479.

82 Perez EA, Rodeheffer R: Clinical cardiac tolerability of trastuzumab. J Clin Oncol 2004;22:322-329.

83 Piccart-Gebhart MJ, Proctet M, Leyland-Jones B, et al.: Trastuzumab after adjuvant chemotherapy in HER2-positive breast cancer. N Engl J Med 2005; 353:1659-1672.

84 Romond EH, Perez EA, Bryant J, et al.: Trastuzumab plus adjuvant chemotherapy for operable HER2-positive breast cancer. N Engl J Med 2005; 353:1673-1684.

85 Guarneri V, Lenihan DJ, Valero V, et al.: Long-term cardiac tolerability of trastuzumab in metastatic breast cancer: The M.D. Anderson Cancer Center experience. J Clin Oncol 2006;24:4107-4115.

86 Chen B, Peng X, Pentassuglia L, et al.: Molecular and cellular mechanisms of anthracycline cardiotoxicity. Cardiovasc Toxicol 2007;7:114-121.

87 Rajagopalan S, Politi PM, Sinha BK, et al.: Adriamycin-induced free radical formation in the perfused rat heart: implications for cardiotoxicity. Cancer Res 1988;4:4766-4769.
88 Wiseman LR, Spencer CM: Dexrazoxane. A review of its use as a cardioprotective agent in patients receiving anthracycline-based chemotherapy. Drugs 1998;56:485-403.

89 Von Hoff D, Rozencweig M, Piccart M: The cardiotoxicity of anticancer agents. Sem Oncol 1982;9: 23-33.

90 Allan A: The cardiotoxicity of chemotherapeutic drugs. Sem Oncol 1992;19:529-542.

91 Keefe DL: Trastuzumab-associated cardiotoxicity. Cancer 2002;95:1592-600.

92 Jessup M, Abraham WT, Casey DE, et al.: Focused update: ACCF/AHA Guidelines for the Diagnosis and Management of Heart Failure in Adults. A report of the American College of Cardiology Foundation/American Heart Association Task Force on Practice Guidelines. Circulation 2009; epub ahead of print.

93 Slamon D, Eiermann W, Robert N, et al.: BCIRG 006: 2nd interim analysis phase III randomized trial comparing doxorubicin and cyclophosphamide followed by docetaxel $(\mathrm{AC} \rightarrow \mathrm{T})$ with doxorubicin and cyclophosphamide followed by docetaxel and trastuzumab $(\mathrm{AC} \rightarrow \mathrm{TH})$ with docetaxel, carboplatin and trastuzumab (TCH) in Her2neu positive early breast cancer patients. Breast Cancer Res Treat 2006;100(suppl 1):abstr 52.

94 Joensuu H, Kellokumpu-Lehtinen P-L, Bono P, et al.: Adjuvant docetaxel or vinorelbine with or without trastuzumab for breast cancer. N Engl J Med 2006;354:809-820.

95 Al-Dasooqi N, Bowen JM, Gibson RJ, et al.: Trastuzumab induces gastrointestinal side effects in Her2overexpressing breast cancer patients. Invest New Drugs 2009;27:173-178.

96 Roché H, Fumoleau P, Spielmann M, et al.: Sequential adjuvant epirubicin-based and docetaxel chemotherapy for node-positive breast cancer patients the FNCLCC PACS 01 Trial. J Clin Oncol 2006; 24:5664-5671.

97 Martin M, Lluch A, Segui MA, et al.: Toxicity and health-related quality of life in breast cancer patients receiving adjuvant docetaxel, doxorubicin, cyclophosphamide (TAC) or 5-fluorouracil, doxorubicin and cyclophosphamide (FAC): impact of adding primary prophylactic granulocyte-colony stimulating factor to the TAC regimen. Ann Oncol 2006;17:1205-1212.

98 Jones S, Holmes FA, O'Shaughnessy J, et al.: Docetaxel with cyclophosphamide is associated with an overall survival benefit compared with doxorubicin and cyclophosphamide: 7-year follow-up of US Oncology Research Trial 9735. J Clin Oncol 2009;27:1177-1183. 